\title{
Norms and Functions in Public Sphere Argumentation
}

\section{J. ANTHONy BLAIR}

University of Windsor

\begin{abstract}
This paper is a commentary on the articles by William Rehg and Robert Asen in this issue of Informal Logic. It compares the subject matter of the two papers, offers an interpretation of and commentary on each paper separately, then discusses their overlapping problematic: the importance of public sphere argumentation.
\end{abstract}

Résumé: On compare le contenu des articles de William Rehg et de Robert Asen publiés dans ce numéro de Informal Logic; on interprète et commente sur ces deux articles séparément, et on discute de leur chevauchement sur la problématique des sphères d'argumentation publique.

Keywords: Rehg, Asen, public sphere, argumentation, argumentation norms, functions of argument, Habermas, Pragma-Dialectics

In this commentary on William Rehg's "Assessing the Cogency of Arguments: Three Kinds of Merits" (2005, see supra, pp. 95-115) and on Robert Asen's "Pluralism, Disagreement, and the Status of Argument in the Public Sphere" (2005, see supra, pp. 117-137), I first address the question of how these two articles relate to each other. Following that discussion, I comment in turn on Rehg's and Asen's articles, and then venture some concluding remarks.

\section{Connections}

How are these two articles related? Rehg proposes "a normative model of argument cogency that acknowledges the difference in levels of analysis and shows how they interrelate" (supra, p. 96). Asen proposes an expansion beyond the justificatory function of argument to others that illustrate the importance of argument in a multiple public sphere conceived as a network. For Rehg, the motivating problems are the lack of congruence between the theories of argument of democratic theorists like Habermas and of transactional theorists like van Eemeren and Grootendorst, and the problems each orientation has in applying to public-sphere argumentation. For Asen, the motivating problem is how public sphere argumentation, which seems to require shared starting points and norms, can play a role in public deliberation in the face of the value pluralism and fundamental disagreement characterizing the (American) public sphere-given the plurality of publics, each with historical participatory norms, and given the differences in the speakers' positions in social hierarchies and networks, both of which can result in unequal

(C) Informal Logic Vol. 25, No. 2 (2005): pp. 139-150. 
advantages in interactions and in the undeserved prominence or marginalization of various arguments. Rehg wants to have workable norms for public sphere argumentation that also relate it to the norms of transactional argumentation and the norms of their component arguments. Asen wants argumentation to have a role to play in public sphere deliberations, in the face of realities that seem to mitigate against its doing so. Rehg and Asen agree about the nature of the public sphere as an argument-space occupied by multiple, overlapping publics. Both regard well-functioning public sphere argumentation as important. If Rehg's model works, then we have norms that apply at all levels to what Asen call's "externally justifying" arguments. Rehg's norms provide grounds for the kinds of critique that Asen and others he cites make of the current space for persuasive argumentation ("external" justification) in the public sphere. If Asen is right, then there are non-justificatory functions of argument that empower those in disadvantaged positions, providing them with new routes of access to participation in public sphere deliberations. So the two articles under consideration connect without competing; their goals and their proposals are compatible, but different. Rehg asks, "How do we assess argumentation at all levels?"; Asen, having assessed public sphere argumentation and found the conditions for it wanting, asks, "How do we find a role for argumentation in the public sphere?"

For purposes of commentary, I have chosen to focus on each article more or less independently of the other, and I will return to a discussion of them jointly in the concluding remarks.

\section{Rehg's model of argument cogency}

William Rehg is proposing, in a densely-suggestive sketch, nothing less than a model that accounts for how all argumentation norms fit together. He motivates the model he proposes as a rapprochement between the norms of local argumentation that involves more or less interpersonal transactions (exemplified by the PragmaDialectical rules) and the norms of public sphere argumentation as these might, as claimed by Habermas, provide legitimacy for legislative actions produced by decisions arrived at using practices and procedures that embody them.

In their present forms, Rehg argues, neither of these two types of argumentation theory can by itself account for the full range of argumentation practice. On the one hand, the counterfactual idealizations of Habermas's communication theory of democratic legitimacy, for instance, need to be applied to particular situations that cannot meet them fully, yet they fail to specify how close the approximations must be to yield legitimacy to the outcomes of the public sphere deliberations. Moreover these ideals (such as openness and freedom from coercion) can conflict in particular situations, yet the ideals fail to specify how such conflicts are to be resolved. Habermasian ideals need to be scaled down. On the other hand, although the procedural rules of the Pragma-Dialectical theory, especially when amplified by use of the felicity conditions specified in speech act theory, apply well to the 
analysis and evaluation of two-party and other similar conversational argumentative exchanges, nevertheless in public sphere argumentation the Pragma-Dialectical rules can no longer apply. For example, they rely on being able to identify interlocutors' commitment stores and agreed-upon starting points, yet multiple arguers simultaneously addressing the same topic intend and understand one another differently. The Pragma-Dialectical rules need to be scaled up.

According to Rehg, Habermas and Pragma-Dialectics share a perspectivist framework towards argumentation as their point of departure. These are perspectives of logic on the product, of dialectic on the procedure or method, and of rhetoric on the process. Arguing is the social process, argumentation is the cooperative procedure, and argument is the product. Habermas's discourse theory of law and democracy, Rehg thinks, points to a fourth, social-institutional level of presuppositions, since Habermas also lists social-institutional constraints, such as those on reaching closure in political deliberation and constraints entailed by systemic imperatives, as well as the influence of historical peculiarities on such things as variations in the ways the rights necessary for public deliberation are specified. These social-institutional presuppositions of argumentation have a normative function by specifying features of the social-institutional environment that sustain or subvert argumentation. Habermas's four-level perspectivism is an ideal model for the social argument-making practices required to permit the members of a society to reach uncoerced mutual understanding, just as the Pragma-Dialectic theory offers an ideal model for argumentative exchanges as two-party transactions to permit interlocutors to resolve disagreements.

Rehg himself favours a perspectivist framework, but not without modifications, for he sees two problems with perspectivism. First, the two triads (product/ procedure/process and logic/dialectic/rhetoric) don't align neatly as product-logic, procedure-dialectic, process-rhetoric. Arguments as products can be and have been assessed from all three perspectives-logical, dialectical and rhetorical-and the same can be expected for argumentation procedures and processes. Rehg's solution is to treat the product/procedure/process trio as three distinct focuses for describing argument-making practices, and to treat the logic/dialectic/rhetoric/ social critique quartet as four sources of norms for analyzing and assessing arguments and argumentation.

Second, in characterizing the process norms as rhetorical, Habermas uses an overly-narrow (and out of date) concept of rhetoric, focussing merely on the process standards necessary for the robust testing of claims, and leaving out contextualized dynamics and presentational moves. Rehg's solution is to think of substantive rhetorical moves such as ethos and pathos, when used appropriately in context, as putting interlocutors in the right frame of mind to best assess argument cogency.

These are interesting repairs to the slippage, which Rehg is right to notice, between these two sets of concepts brought together by perspectivism. The first repair neatly finesses a potential conflation of descriptive and normative perspectives. 
Focus your description on argument as product, on the procedures in play in argumentative interactions, or on the processes at work in arguings. Then each of these can be analyzed and assessed using the norms of logic, dialectic, rhetoric or social critique, either separately or together.

Two wrinkles that this solution doesn't address are that these four loci of norms seem to overlap, and that the norms themselves can conflict. Thus, for example, Johnson (2000) argues that an argument (as product) fails to be logically cogent if it lacks dialectical closure. You haven't given a logically adequate justification of a proposition if you fail to answer well-known objections to it. Conversely, according to the Pragma-Dialectical theory it is a violation of dialectical rules to argue logically invalidly (see van Eemeren and Grootendorst 2004). And Tindale (2004) contends that logical assessment presupposes rhetorical analysis. As for conflicts, Gilbert (1997), as I understand him, holds that there can be cases in which rhetorical norms trump logical ones. The point is not that Rehg is mistaken, or that he oversells his solutions to the slippage problem; it is, rather, a reminder that his solutions don't solve all of the problems connected with perspectivism (not that Rehg claims they do).

Rehg's model envisages three sets of norms. (1) One consists of norms specifying the "content-merits" of the argument textual product. These will be not only logical properties (in a broad sense of logic, for instance permitting domainspecific logical norms) but also dialectical and rhetorical properties, since the textual product assessed by observers or interlocutors in a local transaction will always be an interpretation from a context. From the point of view of the person constructing an argument, in many cases there will be salient characteristics of a special field to which the argument belongs that will have to be honoured, and to the extent that the arguer wishes to address a wider audience, he or she will have to satisfy the standards of cogency that the wider audience can be expected to impose.

A second set of norms specifies "transactional merits." If I correctly understand Rehg, a particular argument in a local transaction has transactional merits only if two conditions are met. (a) The local particular transaction must have identifiable and describable features that place the interlocutors in a position to make responsible judgements of the cogency of the argument (for example, that it satisfies standards and ideals - exemplifies the rules-of appropriate models of good argumentative transactions). I take it that a type of violation would be restrictions on a party's freedom to challenge and respond, or restricted access to relevant information.'

(b) The participants in the transaction must appropriately contextualize these general norms and the texts to which they are applied in their local contexts. That is, they must take into account the social-psychological and institutional conditions under which the texts develop, as well as the rhetorical and dialectical features of the exchange. If I understand this point, there are some nice examples in van Eemeren et al. (1994), Chapter 5, where either the texts cannot be understood as argumentative, or the arguments cannot be correctly interpreted, without 
understanding the situations in which the discourse occurs, and any analysis that was not informed by that contextual information would be almost certain to miss the point. ${ }^{2}$

A third set of norms specify "public merits." I see Rehg again setting forth two conditions that a particular argument used in macrosocial discourse must meet to have public merits. (a) People in different locales and domains must be able to engage the argument and accept it. This condition seems clear enough: people would have to be able to understand one another-for instance, to use terminology in the same way; and people would have to be able to appeal to the same criteria of evaluation and the same factual presuppositions. The other condition is (b) that the social network through which the argument travels must be well structured-that is, the networks and aggregates of dialogue contexts through which the argument travels must have a composition and structure that sustains collective reasonableness.

Rehg adds that the social network is well-structured-collective reasonableness can be expected-only if there are social-institutional grounds for considering the argument to be cogent. These social-institutional grounds must consist, not of abstract or a priori appeals to process idealizations (such as equal voice, or noncoercion), but of the substantive cases made in particular circumstances with respect to particular questions at issue, establishing that those values are in specific ways upheld and specific challenges are refuted. Unless the parties attacking or defending the structure of a social network are required to get down to specifics, the process ideals are simply placeholders-merely possible sites of particular challenges or responses to challenges.

If I understand this last point, an example would be when you and I, as members of the public, appropriately accept medical claims about the effects or safety of drugs on the basis of the testimony of medical researchers. We cannot know all the details of the research, nor understand them. We rely on a system in which medical researchers are well-trained and use appropriate research methodology, are not under pressure to rush to judgement or to ignore worrisome anomalies in experimental outcomes, their publications are carefully and objectively peerreviewed, and so on. A reliable social-institutional network is necessary for us to regard its arguments as sound and to make personal and policy decisions based on them.

We can use the well-structured social network condition, then, as a basis for wariness about the influence of drug manufacturing companies on university medical research, and for condemning that influence in cases like that of Dr. Nancy Oliveri, in which a drug company sought to override a researcher's evidence-based worries about a drug, and also in which her medical school (the University of Toronto), which benefited from the company's research funding, initially supported the drug company. The point is that violations of this condition are extremely threatening to the credibility of public argumentation about public policy in relation to scientific findings. 
An example of a condition that I would think undermines the public merits of political argumentation on American television is the tendency to use oversimplifying and polarizing labels, such as "liberal," "fundamentalist," "right wing," and "left wing." For instance, in the summer of 2005 when a mother who had lost her son in Iraq was making a protest against the U.S.'s war against Iraq near President Bush's ranch in Texas, she was asked by a CNN correspondent if she considered herself to be a "radical" for making this protest-as if her accepting or rejecting that label would convey useful information about her ethos to the television audience, ${ }^{3}$ ignoring or overlooking the fact that such facile, uninformative labelling is almost certain to reinforce stereotypes and harden prejudices.

My initial questions for Rehg's model relate to the issue of for what use or whose use these norms are intended. Is the model proposed for taking an overview perspective, from which we as observers look from outside upon the operations of local argument transactions or of systems of social argumentation practices and procedures and declare them meritorious or flawed? And if so, what is the upshot of these judgements? To what end are we to condemn or congratulate?

These are not rhetorical questions. One possible answer is that we are to use these norms in our roles as policy-makers or critics of policy to guide us in introducing new policies or practices or in identifying flawed ones. For example, if an area of scientific practice is beholden to the interests of a particular company or industry, or to a particular political party or government, or to religious doctrine or some ideology, then the arguments of those practitioners might be open to suspicion about the scientific integrity of the evidence they gather or the use to which they put evidence or theories, or about whether disagreements about scientific theory or its implications are appropriately motivated. Rehg's norms tell us to back up our critique with arguments about the specific ways in which these links have threatened or might threaten objectivity and to provide arguments for specific ways of repairing the situation. Another example: if the manner of news-gathering or reporting in the mass media incorporates distorting and avoidable bias that taints the information conveyed and renders suspect any inferences based on it, then one must show specifically how this happens, and recommend specific reforms, showing in concrete and practical terms how they will ameliorate the situation. In general, using the idea of content, transactional, and public-sphere norms as tools for the observer gives them a role in the critique, reform or creation of argumentative practices or structures that affect those practices.

As my several attempts to think of examples that illustrate the cash value of Rehg's model suggest, in future adumbrations of the theory, perhaps in a booklength treatment where space is available, it would help readers like me if Rehg were to spell out, with reference to specific case studies or examples, just what the model entails concretely. The account in this article is highly general and abstract. In my view the truth of an abstract theory can be ascertained only if it is clear how it cashes out in concrete particular instantiations. 


\section{Asen's multi-functional theory of argumentation}

Robert Asen's motivating problem is how public sphere argumentation, which seems to require shared starting points and shared norms, can play a role in public deliberation in the face of the value pluralism and fundamental disagreement characterizing the American public sphere (and those of other nations)-given the plurality of publics, each with historical participatory norms, and given the differences in the speakers' positions in social hierarchies and networks, both of which can result in unequal advantages in interactions, and in the undeserved prominence or marginalization of various arguments. Asen's solution is not to despair, but to enrich deliberation with other functions besides "external justification"(that is, besides persuasion). He argues that argument can function to reshape the social context within which deliberation (and so justificatory, or persuasive, argumentation) normally occurs, thereby opening the way to resolution and decision-making.

Asen distinguishes between the function of argument for external justification, which is the use of argument to impress one's viewpoint upon another and which has received the lion's share of scholarly attention, and its function for other purposes, among which he identifies three: agenda expansion, responsibility attribution and identity formation. Agenda expansion is the use of argument to widen the public sphere agenda to include the interests and perspectives of marginalized individuals, groups and issues. Responsibility attribution is its use to compel the acceptance of public responsibility for the decisions made in restricted deliberative situations. Identity formation is the use of argument as a means of shaping individual and collective identity.

The internal-justification $v s$. external-justification distinction is extremely important. Asen points out that Toulmin conflates the two, and I think that much theorizing about argument in philosophical circles (if not also elsewhere) has done so too (Blair 2004). I would suggest a slight revision of Asen's conceptualization. "Internal justification" is itself open to two possible interpretations. Where $c$ stands for a position or opinion someone takes or holds, " $c$ is internally justified" might mean that:

(1) $c$ is justified (that is, $c$ is strongly supported) by some reason, $r$ (which consists of a set of propositions, $p_{1}, p_{2}, \ldots p_{\mathrm{n}}$ ); that is, anyone who accepts $p_{1}, p_{2}, \ldots p_{\mathrm{n}}$ is justified in accepting $c$ (with appropriate qualifications and reservations). In other words, there is at least one compelling argument (reason) for $c$;

or

(2) someone, $A$, has (or believes he or she has) a justification in sense

(1) for $c$; that is, $A$ has (or believes he or she has) decisive reasons for his or her position, $c . A$ 's acceptance of $c$ is not arbitrary, or unprincipled, or unreflectively held, or a "mere" opinion, and so on-or so $A$ believes- 
for $A$ has, or believes he/she has, one or more compelling arguments (reasons) for his/her position, $c$. ( $A$ might or might not inform someone else, $B$, of this fact.)

The difference between (1) and (2) is that (1) describes a property of $c$, whereas (2) describes a property of someone's attitude towards $c$.

"External justification," as Asen means it, is different from (1) or (2). " $c$ is externally justified", means:

(3) someone, $A$, tries to get another or others, $B$, to accept $c$, by trying to show that there are reasons for $c$ that $A$ thinks $B$ should accept and $A$ thinks that $B$ should accept that those reasons do indeed compellingly support $c$. In other words, $A$ uses an argument to try to convince $B$ to accept $c$.

A significant difference between (1) and (2), on the one hand, and (3), on the other, is that only the latter describes a communicative act. (Also, someone can externally justify a proposition to another without believing that it is internally justified.) Following Asen's account of their views, and using this tri-fold distinction, Beardsley is talking about (1) and (2), Toulmin conflates (1) and (3), Baird conflates (2) and (3), and Asen wants to contrast (3) with other uses of argument in the public sphere, for he thinks that the model of public sphere argument as exclusively the situation in which one interlocutor tries to persuade another is seriously defective.

In turning to the three other functions of argument that Asen introduces, we must keep in mind that the concept of function is potentially ambiguous. Depending on the context, it can mean inherent purpose (as in: the function of a bread-knife is to cut bread; the function of a screw-driver is to tighten or loosen screws) or it can mean an incidental use to which something is put (as in: bread knives function well for slicing tomatoes; screw-drivers can function well as pries). Do agenda expansion, responsibility attribution and identity formation function as inherent purposes of argument or are they incidental uses to which it can be put? As Asen describes them, they seem to be the latter. I need to document this interpretation by discussing the examples of these other functions that Asen provides, because I want to argue that if it turns out that Asen's examples of functions of arguments describe functions in the sense of incidental uses, and not functions in the sense of inherent purposes, then there is a problem for his argument.

Begin with the Wilson-Rumsfeld example of agenda-formation. It is not clear to me what point exactly Specialist Wilson was trying to make in his question for U.S. Secretary of Defense Rumsfeld, and perhaps it wasn't clear in his own mind. On the face of it he was asking Rumsfeld to explain (and justify?) why U.S. troops in Iraq were, after three years, still not supplied with well-armored vehicles. Perhaps he meant to imply the conclusion that better-armored vehicles ought to be provided immediately. Perhaps he meant to imply the conclusion that someone ought to be held accountable for the lack of essential armor. Perhaps he meant to imply the conclusion that the U.S. should not have invaded Iraq without properly armored 
vehicles. What I doubt is that it was his aim, which as Asen notes was the actual consequence of his making the argument, to add the issue of the state of American planning and preparedness for its war against Iraq to the agenda of the public discussion about the war in the United States.

The Wilson-Rumsfeld example shows that although an arguer's intention can be the goal of persuading or justifying, the actual consequence of the argument can be something different, such as adding an issue to the agenda of public sphere discussion. It is also possible for the arguer to use arguments on the face of it to persuade, but deliberately to intend thereby to achieve some other outcome. A case in point is the argumentation Asen reports against the repeal of the AFDC program at a congressional hearing that everyone knew would not persuade the U.S. House of Representatives committee to withdraw the repeal. In that case, the arguers had as their main objective a by-product of the ostensible persuasive function of arguing. Those testifying went through the motions of making their case against the repeal of the AFDC as if to try to persuade the legislators to change their minds, but with the principal intention of putting their case on record so that those voting for the repeal could be held responsible for explicitly ignoring or overriding those arguments, if and when an opportunity to call them to account were to occur in the future. So here too, although in this case done with full awareness, the use to which the arguments were put is parasitic on their inherent persuasive purpose.

The AFDC example brings to light a new distinction. In addition to the distinction between internal and external justification, we need also to distinguish between the primary and secondary goals of arguers, on the one hand, and the inherent and derivative roles of argument, on the other. My contention is that it is the inherent role of argument to be a justification in any one of the three ways I distinguished above: arguing is, inherently, justifying. For an argument to exist, there must be justification in one of these respects. But to be sure, in doing one thing, one can thereby also (derivatively) do something else. By raising one's hand in certain circumstances, one votes "Aye"; in saying "I will" in other circumstances, one gets married; and so on. Analogously, in arguing, that is, in justifying, one can at the same time also do other things. Moreover, it can be one's primary intention to perform the derivative act. It can be an arguer's primary goal to achieve some other objective by means of externally justifying.

Putting these distinctions to use, we can say that the primary aim of those testifying against the repeal of the AFDC, if Asen's description is correct, was the derivative goal of responsibility attribution. In order to achieve that outcome, they had to go through the motions of putting argument to its inherent use-that is, they had at least to appear to be trying to persuade the House committee not to repeal the AFDC. The situation is similar in Asen's example of the identity-formation function of argumentation. The argument, that the media ought to portray the people in South Central Los Angeles who are talented and hard-working because otherwise it was spreading a distorted image of the community, that was made at a televised event featuring a senior federal official (CIA Director John Deutch), 
was almost certain to have had the effect of strengthening pride in the South Central community and reinforcing the determination of its talented and hardworking people to overcome its prevalent negative image. The identity-formation consequence was a derivative result of the inherent use of argument to persuade, although that result could well have been the arguer's primary objective.

To contend that the agenda-expansion, responsibility-attribution and identityformation functions are derivative functions of argument is not to deny that they are functions of argument and it is not to deny their importance. However, it does raise a question about Asen's enterprise. One of his aims in this article is to rescue public-sphere argumentation from the charge of irrelevance-from Matt Miller's lament that persuasion is dead. Asen asks: Where is the space for argument in the face of value pluralism and fundamental disagreement? His answer is that while the persuasive function of public-sphere argument might be on shaky ground, its agenda-expansion, responsibility-attribution and identity-formation functions can remain healthy even with contemporary value pluralism, deep disagreement, and inequalities of power in the public sphere. However, if I am right that these latter functions are derivative, and dependent upon the inherent function of persuasion or justification, then unless the inherent uses of argument in the public sphere are somehow motivated - unless people have some reason for at the very least going through the motions of making arguments to persuade or justify - there will be no activity on which the functions Asen identifies can piggy-back. So Asen is brought back to face Miller's question: is there a point in trying to persuade anyone or to justify yourself in public-sphere argumentation?

\section{Concluding remarks}

The upshot of what I am suggesting is that if there is no longer any possibility for persuasion in any public sphere, that implies that there are no longer any public spheres. A public sphere is, among other things, a forum in which the members of its public seek to persuade one another of the plausibility of beliefs and the desirability of actions. As Taylor argues (1995, Ch. 13), a public sphere, as an ideal type, is open to everyone equally and exists outside the political domain. As such, members of its public enter it as equals. The Private and the U.S. Secretary of Defense, the community activist and the Director of the Central Intelligence Agency, the ordinary citizen and the American House of Representatives sub-committee chair, have as participants in the public sphere only whatever personal ethos they can muster to lend weight to the force of their arguments. There will always be differences in power among members of any public and so among participants in public sphere deliberations. But these power differences are to be left at the door of the deliberative forum. The major danger to public sphere deliberations occurs when the public sphere becomes politicized. The public sphere is politicized, in the sense I have in mind, when the participants tend to be assumed to be already parti pris-committed beyond the reach of rational argumentation to a position or point of view. The only 
motive such a person can reasonably have to engage in an argumentative discussion is to try to win over the few remaining uncommitted parties. In such circumstances, the idea of being moved by the strength of the better argument, by the preponderance of the evidence, by the more comprehensive and internally consistent theory, gets no traction. The ideal of listening to what others have to say, of weighing as many and as varied views as possible, before making up one's mind, has no place. Thus if the public sphere becomes completely politicized, it ceases to exist. There is no longer the possibility of persuasion.

What has happened, in that case, is that Rehg's norms for public sphere argumentation are completely violated. There is no reason to engage in argumentation or to accept it, and there is no longer any collective reasonableness. Thus these norms are not just guidelines; they specify the very conditions of the possibility of public sphere argumentation.

To the extent that participants in public deliberation weigh in with the power of their office rather than with the force of their arguments, they operate as destructively towards the public sphere as do ideologues. Thus, measures that bring issues that the powerful want suppressed onto the agenda for public deliberation, that hold the powerful to account in the forum of public deliberation, and that give the powerless the sense of identity to participate in public spheres, all serve to reinvigorate the public sphere. So the functions of argument that Asen draws our attention to are particularly salient when the powerful threaten the integrity of the public sphere. And if, as I have argued, such measures rely on the possibility of persuasive argument in the public sphere, there is a sense in which the public sphere can, and must, reinvigorate itself. If persuasion becomes impossible, then the other functions of argument that supervene on its persuasive function, such as agenda setting, responsibility attribution or identity formation, also cease to be possible.

\section{Notes}

'In the September 2005 issue of Vanity Fair, in the "Letter from Washington" column, there is a story by David Rose, "An Inconvenient Patriot," about the U.S. Federal Bureau of Investigation's response to an allegation by one of its contract employees that another employee was engaged in suspicious activity, possibly espionage. According to Rose's story, the F.B.I. not only refused to investigate the allegation, but it threatened the person who made it and shortly thereafter terminated her contract. If this is true, then the F.B.I. refused to respond to the allegation in a way that would permit responsible judgements of the cogency of the accuser's evidence. Its response failed to have any transactional merit.

${ }^{2}$ For instance, example 5.2 (p. 97):

A: We have eight ounces left. That should last us for a couple of days at least.

B: Heh yeah, I guess so.

A: Twenty-four days I would estimate.

B: Eight ounces?!

A: Sure. We smoke a lid in two or three days.

B: That's like- that's like drinking eight or nine kegs every week. 
C: Or smoking two packs of cigarettes every day.

D. EHHH-heh-he-heh-heh

B: Yeah. Only I don't smoke two packs of cigarettes every-

C: Three? Four?

B: No. Not nearly that many

Here the significance of B's keg analogy is completely lost without the background information that $\mathrm{A}, \mathrm{B}, \mathrm{C}$ and D view themselves as superior to beer-drinking "fraternity boys."

Or example 5.4 (p.103):
A: I'm getting fat again.
B: You are not.
A: Yes I am.
B: You've got no buns.
A: I've got the puffy stomach though.
B: Don't worry about it. No one but you can even notice it.

Here B's final comment will wrongly be considered irrelevant if the issue is take to be whether A is getting fat; what is really going on is that $\mathrm{A}$ is seeking reassurance that she is attractive.

${ }^{3}$ In the event, her answer to the stupid question turned out to strengthen her ethos: she said she didn't think she was a radical, but she guessed she was radical in her opposition to the U.S. military involvement in Iraq - an answer that neatly avoided the labelling trap while leaving the impression of a thoughtful and honest person.

\section{References}

Asen, Robert. (2005). "Pluralism, Disagreement, and the Status of Argument in the Public Sphere." Informal Logic 25: 117-137.

Blair, J. Anthony. (2004). “Argument and Its Uses.” Informal Logic, 24.2:137-151.

Johnson, Ralph H. (2000). Manifest Rationality. Mahwah, NJ: Lawrence Erlbaum.

Eemeren, Frans H. van and Rob Grootendorst. (2004). A Systematic Theory of Argumentation. Cambridge: Cambridge University Press.

Eemeren, Frans H. van, Rob Grootendorst, Sally Jackson and Scott Jacobs. (1994) Reconstructing Argumentative Discourse. Tuscaloosa/London: University of Alabama Press.

Gilbert, Michael. (1997). Coalescent Argument. Laurence Erlbaum Associates.

Rehg, William. (2005). "Assessing the Cogency of Arguments: Three Kinds of Merits." Informal Logic, 25: 95-115.

Taylor, Charles. (1995). Philosophical Arguments. Cambridge, MA: Harvard University Press.

Tindale, Christopher W. (2004). Rhetorical Argumentation. Thousand Oaks, CA: Sage Publications.

J. Anthony Blair

Department of Philosophy

University of Windsor

Windsor, Ontario, N9B $3 P 4$

Canada 